\title{
Polyphyllin I Inhibits Propionibacterium acnes-Induced Inflammation In Vitro
}

\author{
Tingting Zhu, ${ }^{1}$ Wenjuan Wu, ${ }^{1}$ Shuyun Yang, ${ }^{1}$ Donglin Li, ${ }^{1}$ Dongjie Sun, ${ }^{1}$ and Li He ${ }^{1,2}$
}

\begin{abstract}
Propionibacterium acnes (P. acnes) has been implicated in the progression of acne inflammation. Because current acne medications have various side effects, it is necessary to explore alternative medications possessing anti-inflammatory activity against $P$. acnes. We investigated the inhibitory effects of polyphyllin I (PPI) on P. acnes-induced inflammation in vitro. In this study, we examined the effects of PPI on the production of inflammatory cytokines in HaCaT keratinocytes treated with heat-killed $P$. acnes. These treated $\mathrm{HaCaT}$ keratinocytes showed increased expression of Toll-like receptor 2 (TLR2) and production of inflammatory cytokines. PPI significantly suppressed the secretion of inflammatory cytokines, including interleukin (IL)-6, IL-8, and tumor necrosis factor (TNF)- $\alpha$, and the expression of TLR2 in P. acnes-treated cells. Moreover, we studied the influence of PPI on the nuclear factor- $\mathrm{kB}(\mathrm{NF}-\mathrm{kB})$ and mitogen-activated protein kinase (MAPK) signaling pathways in $P$. acnes-treated keratinocytes. PPI diminished the activation of NF- $\mathrm{KB}$. Phosphorylated p38 levels were markedly increased after treatment with heat-killed $P$. acnes but were decreased after treatment with PPI, while the effect of PPI on ERK phosphorylation was not significant. Heat-killed P. acnes and PPI did not have any effect on JNK phosphorylation. Furthermore, we confirmed that NF-kB p65 inhibitor (BAY11-7082), p38 MAPK inhibitor (SB203580), and PPI blocked the expression of IL-8 in heat-killed P. acnes-treated cells. These results demonstrated that PPI has potential for development as a treatment for acne inflammation.
\end{abstract}

KEY WORDS: P. acnes; TLR2; NF-kB; MAPK; polyphyllin I.

\section{INTRODUCTION}

Acne vulgaris is the 8th most common disease in the world, affecting more than $80 \%$ of individuals at

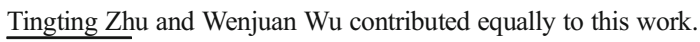

Electronic supplementary material The online version of this article (https://doi.org/10.1007/s10753-018-0870-z) contains supplementary material, which is available to authorized users.

${ }^{1}$ Department of Dermatology, First Affiliated Hospital of Kunming Medical University, Kunming, 650032, China

${ }^{2}$ To whom correspondence should be addressed at Department of Dermatology, First Affiliated Hospital of Kunming Medical University, Kunming, 650032, China. E-mail: helikm2662@126.com some time during their lives $[5,9]$. Although this is not a fatal disease, inflammatory lesions can persist for a long time, ultimately resulting in permanent scarring on the face of those with severe cases and causing serious physical and psychosocial morbidities [23]. Four factors have been identified to play critical roles in the pathogenesis of acne: sebum hyperproduction, altered follicular keratinization, Propionibacterium acnes (P. acnes) colonization and proliferation, and immune reaction and inflammation [15]. At present, it is widely accepted that acne is an inflammatory disease, inflammation is involved in all acne-related processes, and inflammatory events are involved in initiating acne lesions [3, 13, 22]. 
P. acnes, a common Gram-positive anaerobic bacterium, is part of the normal skin flora and plays an important role in acne pathogenesis. P. acnes stimulates the production of various inflammatory cytokines through Toll-like receptor (TLR) 2 and, to a lesser extent, TLR4, contributing to acne inflammation $[14,17]$. Furthermore, P. acnesactivated TLR2 promotes the activation of the MAPK and NF-KB signaling pathways, which are responsible for inflammatory cytokine production and the innate immune response [11]. Therefore, the $P$. acnes-induced inflammatory response participates in acne pathogenesis, at least in part due to the activation of TLR2 and its downstream signaling pathways, namely, the MAPK and NF-KB pathways.

Antibiotics and isotretinoin are frequently used therapeutic agents for acne inflammation, but they have potentially serious detrimental effects [27]. Therefore, there is an increasing need to identify new anti-acne ingredients, especially natural products with relative safety. Paris polyphylla has been widely used as a natural medicine in the treatment of infectious and inflammatory diseases and of cancer in traditional Chinese medicine for approximately 2000 years [26]. In 2015, Paris polyphylla was officially documented as an anti-inflammatory and hemostatic agent in the Chinese Pharmacopoeia [26]. Polyphyllin I (PPI), a major steroidal saponin extracted from Paris polyphylla rhizomes, displays proapoptotic and anti-tumor effects $[1$, $4,7]$. However, no studies have shown the role and underlying mechanism of PPI-mediated anti-inflammatory activity. We aimed to evaluate the effects of PPI in P. acnesinduced inflammation in vitro.

\section{MATERIALS AND METHODS}

\section{Materials}

The strain of P. acnes (ATCC6919, Xiangfu Biotech, Shanghai, China) was obtained from the American Type Culture Collection. The bacteria were cultured in brain heart infusion (BHI) broth (Rishui Biotechnology, Qingdao, China) under anaerobic conditions. The HaCaT cell line was purchased from the cell bank of the Type Culture Collection of the Chinese Academy of Sciences (Shanghai). Cells were grown in RPMI 1640 medium (Gibco BRL, NY) supplemented with $10 \%$ heat-inactivated fetal bovine serum (FBS) (Gibco), streptomycin $(100 \mu \mathrm{g} / \mathrm{ml})$, and penicillin $(100 \mathrm{U} / \mathrm{ml})$ at $37{ }^{\circ} \mathrm{C}$ in a humidified atmosphere with $5 \% \mathrm{CO}_{2}$. PPI was purchased from the Institute for Drug Control (Shanghai, China, \#111590) and dissolved in dimethyl sulfoxide (DMSO). BAY11-7082 and SB203580 were purchased from Sigma (St. Louis, MO, USA).

\section{Preparation of $P$. acnes}

P. acnes was cultured in the exponential phase for 2 days and in the stationary phase for 3 days. The bacteria were harvested by centrifugation at $2500 \mathrm{rpm}$ for $5 \mathrm{~min}$ at $4{ }^{\circ} \mathrm{C}$. The bacterial pallets were washed in cold phosphatebuffered saline (PBS) and centrifuged three times. Finally, the $P$. acnes pellet was resuspended in PBS. To obtain heatkilled bacteria, the bacterial suspension was heated at $70{ }^{\circ} \mathrm{C}$ for $30 \mathrm{~min}$, and the supernatant was removed by centrifugation at $10,000 \mathrm{rpm}$ for $5 \mathrm{~min}$ at $4{ }^{\circ} \mathrm{C}$. This processed pellet was used for subsequent experiments.

\section{Cell Viability Assay}

The effects of PPI on $\mathrm{HaCaT}$ cell viability were determined by the Cell Counting Kit- 8 (CCK-8 assay: Dojindo Laboratories, Japan). CCK-8 assays were used to assess the rate of cellular proliferation and to quantify cell viability. In brief, $\mathrm{HaCaT}$ cells were seeded in 96-well plates with $100 \mu \mathrm{l}$ of medium at a density of $2 \times 10^{5}$ cells/ well. After the cells were incubated with different concentrations of PPI $(0,0.3,0.6,0.9$, and $1.2 \mu \mathrm{g} / \mathrm{ml})$, $10 \mu \mathrm{l}$ of CCK-8 solution was added to each well, and the plates were incubated for $1 \mathrm{~h}$ at $37^{\circ} \mathrm{C}$. Finally, we determined the optical density (OD) at $450 \mathrm{~nm}$ using a Microplate Reader (BioTek, USA). All experiments were conducted in triplicate.

\section{Enzyme-Linked Immunosorbent Assay}

Cultured $\mathrm{HaCaT}$ cells were challenged with $P$. acnes (ATCC6919) at $0,1.0 \times 10^{5}, 1.0 \times 10^{6}$, and $1 \times 10^{7} \mathrm{CFU}$. The following cytokines were determined: IL-6, IL-8, and TNF- $\alpha$. An enzyme-linked immunosorbent assay (ELISA) kit (RD Systems, Minneapolis, MN) for each cytokine was used to determine the expression level according to the manufacturer's instructions. As described in previous studies, $\mathrm{HaCaT}$ cells were seeded in 96-well plates at a density of $2 \times 10^{5}$ cells $/$ well in FBS-free medium and pretreated with different concentrations of PPI $(0,0.3,0.6$, and $0.9 \mu \mathrm{g} / \mathrm{ml}$ ) for $2 \mathrm{~h}$, followed by stimulation with heatkilled $P$. acnes $\left(1 \times 10^{7} \mathrm{CFU} / \mathrm{ml}\right)$ for $24 \mathrm{~h}$. Cell-free supernatants were analyzed by ELISA for IL-6, IL-8, and TNF$\alpha$. In addition, the cells were pretreated with DMSO, PPI $(0.9 \mu \mathrm{g} / \mathrm{ml})$, or SB203580 $(20 \mu \mathrm{mol})$ for $2 \mathrm{~h}$, followed by stimulation with heat-killed P. acnes $\left(1 \times 10^{7} \mathrm{CFU} / \mathrm{ml}\right)$ for 
24 h. Cell-free supernatants were analyzed for IL-8. All experiments were performed three independent times.

\section{Quantitative Real-Time Polymerase Chain Reaction}

HaCaT cells were adjusted to a density of $2 \times 10^{5}$ cells/well in serum-free medium and seeded in 6-well plates. Cells were pretreated with different concentrations of PPI $(0.3,0.6$, and $0.9 \mu \mathrm{g} / \mathrm{ml})$ for $2 \mathrm{~h}$. Next, cells were stimulated with heat-killed $P$. acnes for $8 \mathrm{~h}$, followed by harvesting and rinsing. The control group was incubated without PPI or bacteria. Total RNA was isolated from cells using an RNA extraction kit following the manufacturer's instructions and quantified with a spectrophotometer at $260 \mathrm{~nm}$. A reverse-transcription kit (Takara, Shiga, Japan) was used to synthesize cDNA. qRT-PCR was conducted as follows: initial denaturation at $95^{\circ} \mathrm{C}$ for $30 \mathrm{~s}$, followed by 40 cycles of $95^{\circ} \mathrm{C}$ for $5 \mathrm{~s}, 60^{\circ} \mathrm{C}$ for $30 \mathrm{~s}$, and $72{ }^{\circ} \mathrm{C}$ for $60 \mathrm{~s}$. The primer sets for TLR2, IL-1 $\alpha$, keratin 16 (K16), and GAPDH were purchased as QuantiTect primer assays (Sangon Biotech, Shanghai). GAPDH was used as an endogenous control.

\section{Western Blot Analysis}

Cells were harvested, and total protein was extracted from each sample, separated by $10 \%$ SDS-PAGE, and then transferred to a polyvinylidene difluoride (PVDF) membrane. After being blocked in 5\% skim milk for $2 \mathrm{~h}$ at room temperature, the membranes were incubated overnight at $4{ }^{\circ} \mathrm{C}$ with primary antibodies [K16 mouse antibody (Santa Cruz Biotechnology, Santa Cruz, CA); IL-1 $\alpha$ mouse antibody (R\&D Systems, Minneapolis, MN); TLR2 rabbit antibody (Abcam, Massachusetts, UK); and p-38, p-p38,

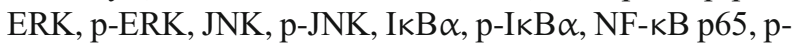
NF- $k B$ p65, and GAPDH antibodies (Cell Signaling Technology, Inc., MA, USA)]. The membranes were then washed in TBST and incubated with HRP-conjugated secondary $\mathrm{IgG}$ antibody at room temperature for $1 \mathrm{~h}$. The bands were visualized by an ECL kit and exposed with an Amersham Imager (General Electric Company, USA). The data represent three independent experiments.

\section{Immunofluorescence Assay}

HaCaT cells treated or untreated with PPI, stimulated or unstimulated with $P$. acnes, were harvested and rinsed. Next, cells were washed with $0.01 \mathrm{M}$ phosphate-buffered saline (PBS) and fixed in $4 \%$ paraformaldehyde at room temperature for $30 \mathrm{~min}$. After being permeabilized with a penetrating agent $(0.2 \%$ Triton $\mathrm{X}-100)$ for $20 \mathrm{~min}$, and blocked with $5 \%$ BSA for $1 \mathrm{~h}$, cells were blocked with PBS containing 5\% bovine serum albumin for $1 \mathrm{~h}$ at room temperature and then resuspended in $100 \mu$ l of diluted NFKBp65 antibody (1:200, Cell Signaling Technology, Inc., MA, USA), and incubated overnight at $4{ }^{\circ} \mathrm{C}$. Cells were rinsed and incubated with fluorescein isothiocyanatelabeled goat anti-rabbit secondary antibody (1:1000, Cell Signaling Technology, Inc., MA, USA) for $1 \mathrm{~h}$ in the dark, followed by staining with DAPI for $3 \mathrm{~min}$. Finally, these slides were sealed by anti-fluorescence mounting medium and observed under confocal laser fluorescence microscope (Carl Zeiss Zen 2008, Carl Zeiss Inc., Germany).

\section{Flow Cytometry Detection}

A suspension of $10^{6}$ cultured HaCaT cells stimulated or unstimulated with $P$. acnes was prepared and permeabilized to detect TLR2 and TLR4 protein expression. The cells were collected and washed twice with PBS, then stained with $5 \mathrm{ml}$ purified anti-human TLR2 and TLR4 antibody (Abcam, Massachusetts, UK) at $4{ }^{\circ} \mathrm{C}$ for $30 \mathrm{~min}$ protected from light. After washing twice with PBS, the cells were collected by low-speed centrifugation (1500 r, $10 \mathrm{~min}$ ) and incubated with $2 \mu \mathrm{l}$ PE-conjugated goat anti-rabbit IgG mAb (Abcam, Massachusetts, UK) at $4{ }^{\circ} \mathrm{C}$ for $30 \mathrm{~min}$ in the dark, followed by two washes with PBS. Finally, the stained cells were suspended in $500 \mathrm{ml}$ PBS, and analyzed by flow cytometry. The negative control was processed in the same way but without the anti-TLR2 and TLR4 antibodies.

\section{Statistical Analysis}

Statistical analysis was performed using Statistical Package for Social Sciences (SPSS, version 19, IBM, Armonk, NY, USA). The results are presented as the means \pm standard deviations. Differences among groups of data were analyzed using one-way analysis of variance (ANOVA). A value of $P<0.05$ indicated statistical significance.

\section{RESULTS}

\section{$P$ acnes Induced the Secretion of Inflammatory Cytokines and the Expression of TLR2 in HaCaT Cells}

We first verified that $P$. acnes induces the secretion of inflammatory cytokines. The levels of inflammatory cytokines released by $P$. acnes-stimulated $\mathrm{HaCaT}$ cells were detected by ELISA. Untreated HaCaT cells secreted low 
levels of IL-6, IL-8, and TNF- $\alpha$, while treatment with heatkilled $P$. acnes significantly upregulated the levels of these cytokines in a concentration-dependent manner (Fig. 1ac). In particular, IL-8 expression levels were markedly increased. Several papers have reported that $P$. acnes may induce an inflammatory response via the activation of TLR2 and TLR4, which are expressed on the surface of $\mathrm{HaCaT}$ keratinocytes $[14,17]$. Consistent with the results of previous studies, TLR2 expression levels were significantly increased following P. acnes stimulation (Fig. 1d-f).

\section{PPI Reduced the Secretion of Inflammatory Cytokines by $P$. acnes-Treated HaCaT Cells}

We investigated the toxicity of PPI at different concentrations $(0.3,0.6,0.9$, and $1.2 \mu \mathrm{g} / \mathrm{ml})$ and time points ( 24 and $48 \mathrm{~h}$ ) in CCK-8 assays to choose a suitable concentration range and time point for subsequent experiments. The results are shown in Fig. 2a. After 24 and $48 \mathrm{~h}$, PPI exhibited no toxicity against $\mathrm{HaCaT}$ keratinocyte viability at a concentration of $0.3-0.9 \mu \mathrm{g} / \mathrm{ml}$. We tested the antibacterial activity of PPI in preliminary experiments. The MIC of PPI was $0.625 \mathrm{mg} / \mathrm{ml}$, while the maximum tested concentration of PPI in the current study was $0.9 \mu \mathrm{g} / \mathrm{ml}$. Therefore, PPI showed little effect on the growth of $P$. acnes at this concentration. On the basis of these results, concentrations of $0.3,0.6$, and $0.9 \mu \mathrm{g} / \mathrm{ml}$ PPI were used in subsequent experiments. We examined the effects of PPI on the secretion of inflammatory cytokines by $\mathrm{HaCaT}$ cells treated with $P$. acnes. Supporting its potential anti-inflammatory effects, PPI decreased the expression levels of IL-6, IL-8, and TNF- $\alpha$ in a dose-dependent manner (Fig. 2b-d).

\section{PPI Decreased the Transcription and Expression of TLR2 in P. acnes-Treated HaCaT Cells and Potentially Modulated the Dyskeratosis of Epidermal Keratinocytes}

In accordance with our previous findings, we observed that TLR2 was activated in HaCaT keratinocytes following $P$. acnes exposure, but PPI significantly reduced TLR2 mRNA and protein expression in a concentrationdependent manner (Fig. 3a-e). In addition, PPI significantly downregulated the mRNA and protein expression of IL$1 \alpha$ (Fig. 3b-e), a strong stimulator of follicular hyperkeratosis, and inhibited the expression of K16 (Fig. 3c-e), a marker of epidermal proliferation and abnormal differentiation, in heat-killed P. acnes-treated HaCaT keratinocytes. Follicular epidermal dyskeratosis is one of the major triggers of acne pathogenesis. We examined the possible beneficial effects of PPI on the hyperproliferation and abnormal differentiation of $P$. acnes-treated $\mathrm{HaCaT}$ cells.

\section{PPI Inhibited the Activation of the NF-KB and MAPK Signaling Pathways in P. acnes-Treated HaCaT Cells}

To investigate whether the NF- $\mathrm{KB}$ signaling pathway is involved in the anti-inflammatory properties of PPI, we examined the expression profile of NF-KB-related proteins by western blotting. We found that phosphorylated $\operatorname{I} \kappa \mathrm{B} \alpha$ and NF-KB p65 levels were significantly upregulated after $P$. acnes treatment but were downregulated by co-treatment with PPI (Fig. 4a, b). We used immunofluorescence staining to examine the location of NF-KB p65 in HaCaT cells. We discovered that NF- $\mathrm{kB}$ p65-positive staining was predominately localized in control cytoplasm and shifted to the nuclei with $P$. acnes stimulation. Interestingly, the $P$. acnes-induced translocation of NF-kB p65 was suppressed in the presence of PPI (Fig. 4e).

MAPK activation is important in the regulation of the inflammatory response. The phosphorylation of p38 was significantly upregulated in $\mathrm{HaCaT}$ keratinocytes following $P$. acnes treatment, and ERK phosphorylation slightly increased (Fig. 4c, d). In contrast, PPI inhibited P. acnesinduced $\mathrm{p} 38$ phosphorylation in a concentration-dependent manner. However, the effect of PPI on ERK phosphorylation was not significant (Fig. 4c, d). Moreover, treatment with $P$. acnes and PPI did not have any effect on JNK phosphorylation (Fig. 4c, d). Additionally, the NF-kB p65 inhibitor (BAY11-7082), p38 MAPK inhibitor (SB203580), and PPI inhibited IL-8, TNF- $\alpha$, and IL-6 expression in heat-killed P. acnes-treated cells (Fig. 4f and Supplemental Figs. 1 and 2).

\section{DISCUSSION}

Acne vulgaris is a chronic inflammatory skin disorder that affects the pilosebaceous unit. Although the exact pathogenesis of acne vulgaris has not yet been elucidated, it has been verified that $P$. acnes colonization and proliferation play important roles in the development of acne inflammation $[22,30]$. P. acnes promotes the activation of TLR2 in keratinocytes, aggravating inflammation reactions $[14,17]$. In fact, TLR activation leads to activation of the MAPK and NF-KB signaling pathways [24]. MAPK activation is important for mediating the signaling cascades that regulate NF-KB activation [28, 32]. In addition, activation of both MAPK and NF- $K B$ have been found in acne lesions, suggesting that the MAPK and NF-KB signaling 

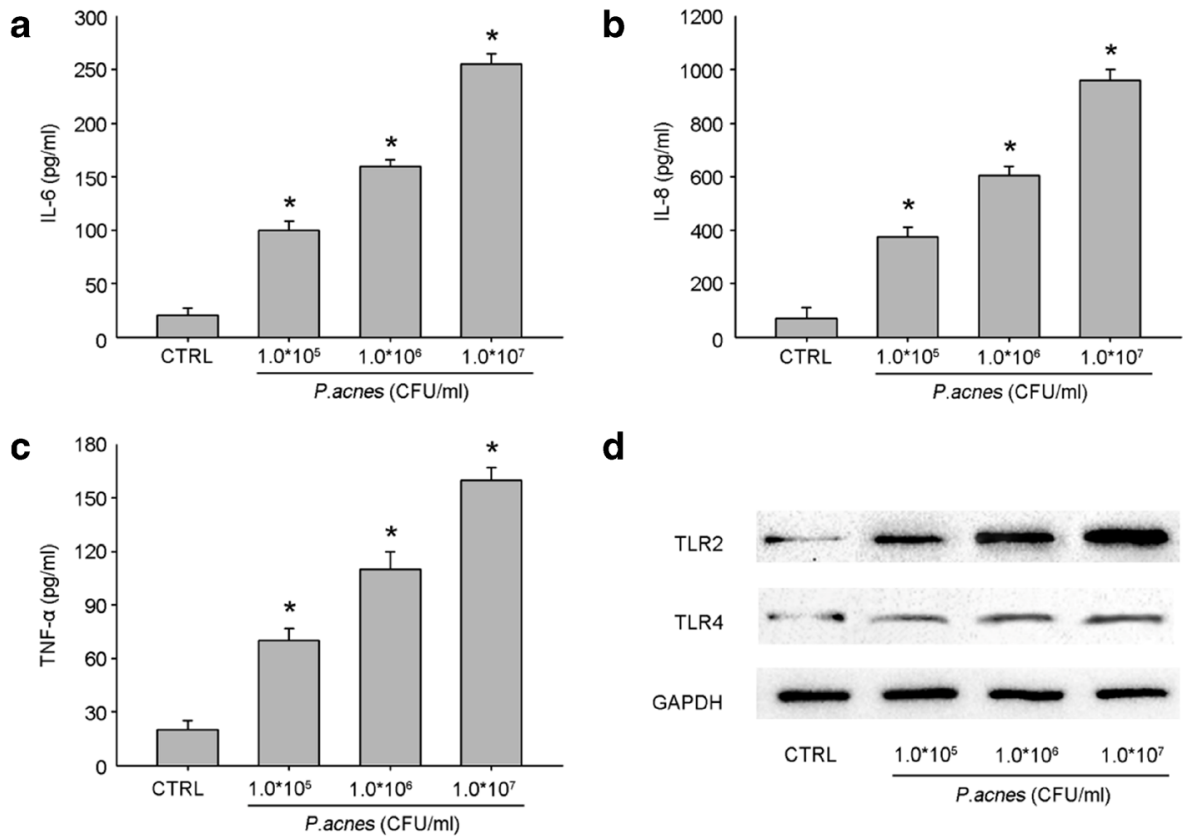

d

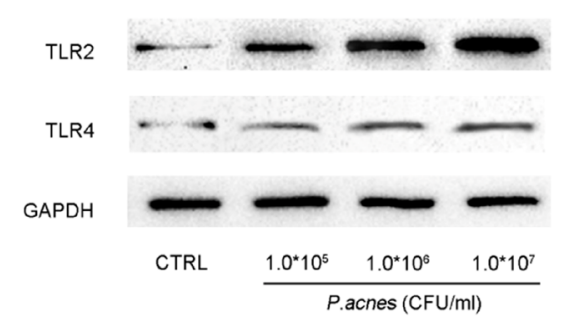

e
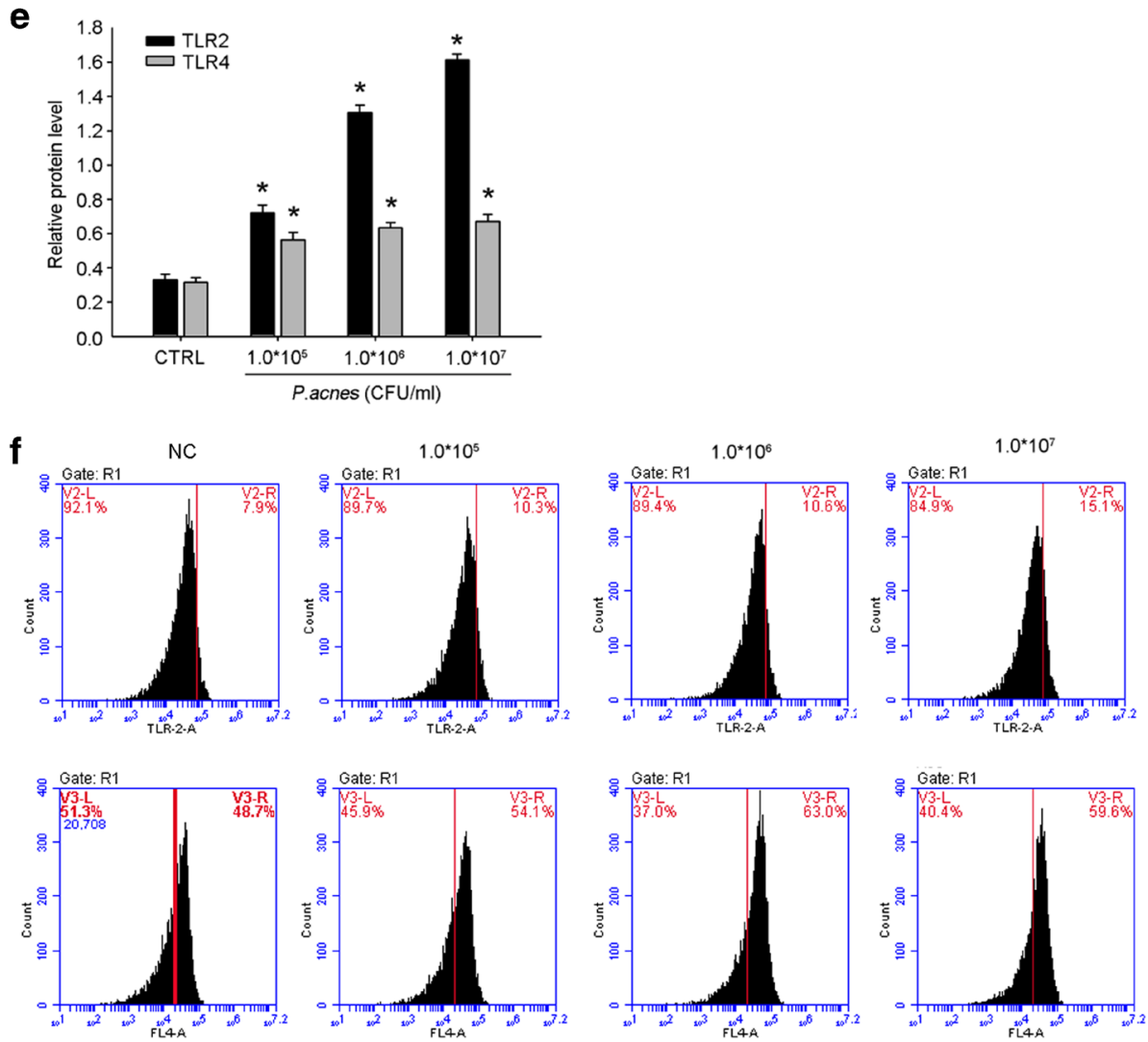

Fig. 1. Heat-killed P. acnes induced inflammatory cytokine production in HaCaT cells. HaCaT cells were treated with heat-killed $P$. acnes. ELISA results with culture medium show that IL-6, IL-8, and TNF- $\alpha$ were increased by heat-killed $P$. acnes $(\mathbf{a}-\mathbf{c})$. Western blot analysis and flow cytometry demonstrate that TLR2 and 4 were increased by heat-killed $P$. acnes $(\mathbf{d}-\mathbf{f})$. Results are expressed by mean $\pm \mathrm{SE}$ of three independent determinations. $* P<0.05$ compared with the control group. 

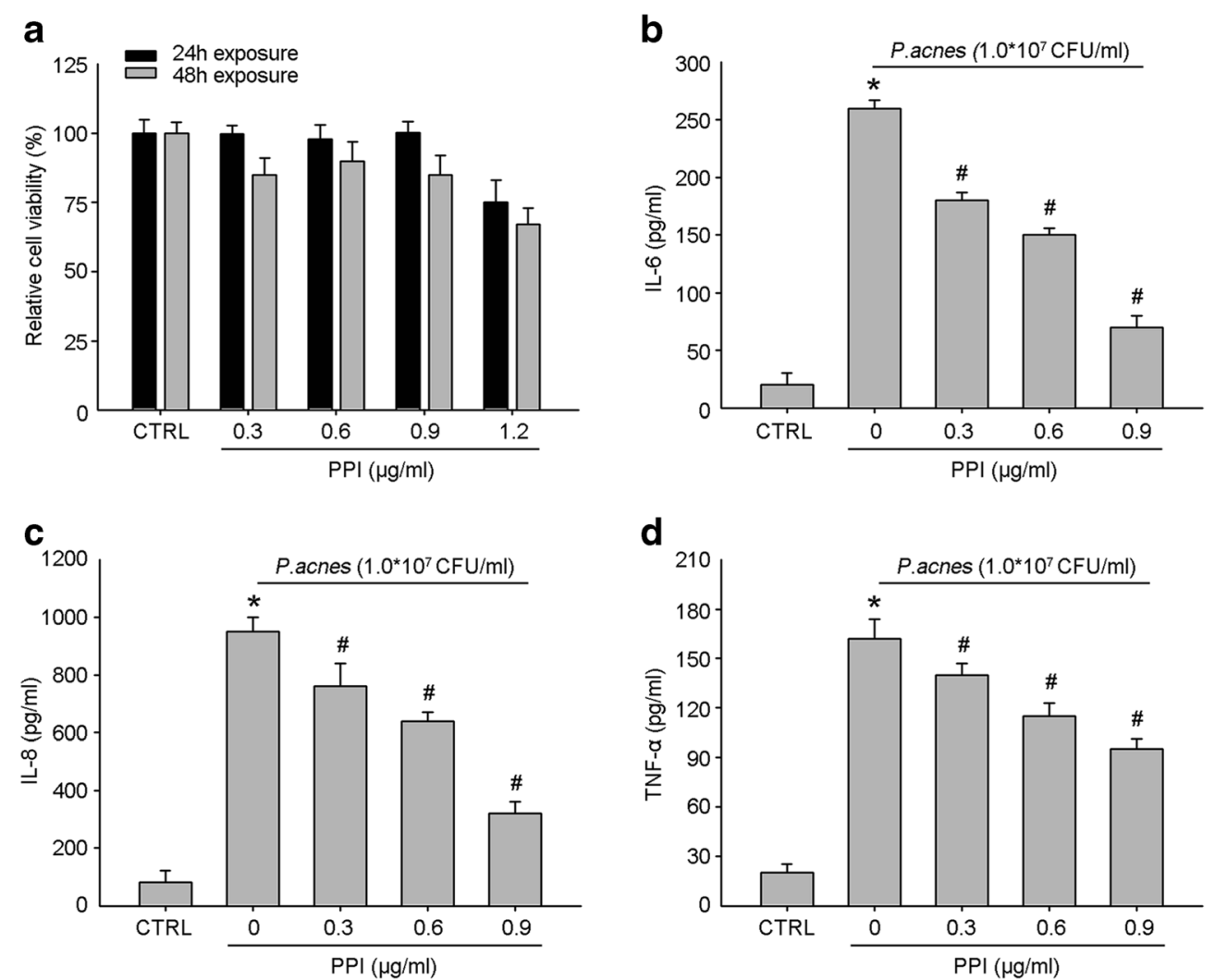

Fig. 2. Effects of PPI on viabilities of $\mathrm{HaCaT}$ cells and the production of inflammatory cytokines. (a) Cells were exposed to PPI (at $0-1.2 \mu \mathrm{g} / \mathrm{ml}$ concentration) for 24 (black bars) and $48 \mathrm{~h}$ (gray bars). HaCaT cells were co-incubated with different concentrations $(0.3,0.6,0.9 \mu \mathrm{g} / \mathrm{ml})$ of PPI for $2 \mathrm{~h}$, and then stimulated with heat-killed $P$. acnes for $24 \mathrm{~h}$. The culture supernatants were subsequently isolated and analyzed for IL-6 (b), IL- 8 (c), and TNF- $\alpha$ (d) production. A control group without $P$. acnes stimulation was conducted in paralleled. Data are the mean $\pm \operatorname{SE}(n=3)$. * $P<0.05$ between control and each $P$. acnes-stimulated group, $\# P<0.05$ between the $P$. acnes-treated group, PPI non-treated group, and each PPI-treated group.

pathways are important for the pathogenesis of acne vulgaris $[18,30]$. Therefore, suppressing the activation of MAPK and NF-KB has a protective effect on acne inflammation.

PPI is an ethanol extract of Paris polyphylla Smith var. yunnanensis (Franch.) Hand.-Mazz., a natural herb that has been frequently used in traditional medicine for the treatment of hemostasis, snakebite, psoriasis, and abscesses for thousands of years [26]. Steroidal saponins, phytosterols, phytoecdysones, flavonoids, and fatty acid esters are the main components of P. polyphylla var. yunnanensis [31]. Among them, steroidal saponins such as polyphyllin I (PPI), II (PPII), VI (PPVI), and VII (PPVII) are the main active constituents [26, 31]. Studies have shown a direct effect of $P$. acnes on keratinocytes via interaction with TLR2 that induces the production of various inflammatory cytokines, thereby promoting acne inflammation [10]. Moreover, there is a positive correlation between the severity of acne inflammation and TLR2 expression levels [2]. Zinc salts and systemic isotretinoin are effective against inflammatory acne via reduction in TLR2 expression in human keratinocytes [2, 12]. Therefore, we analyzed PPI in subsequent experiments to investigate whether PPI inhibits the production of common inflammatory cytokines and the expression of TLR2 as well as its downstream signaling pathways.

In our current study, TLR2 mRNA and protein expression levels in $\mathrm{HaCaT}$ cells were significantly increased after $P$. acnes treatment; however, PPI suppressed TLR2 expression. Follicular epidermal dyskeratosis is one of the major triggers of acne pathogenesis. IL- $1 \alpha$ induces hypercornification of the infundibulum in a manner similar to that seen in comedones $[8,21]$. K16, a marker of epidermal proliferation and abnormal differentiation, is upregulated in all hyperproliferative and abnormally differentiating suprabasal keratinocytes [29]. We examined 

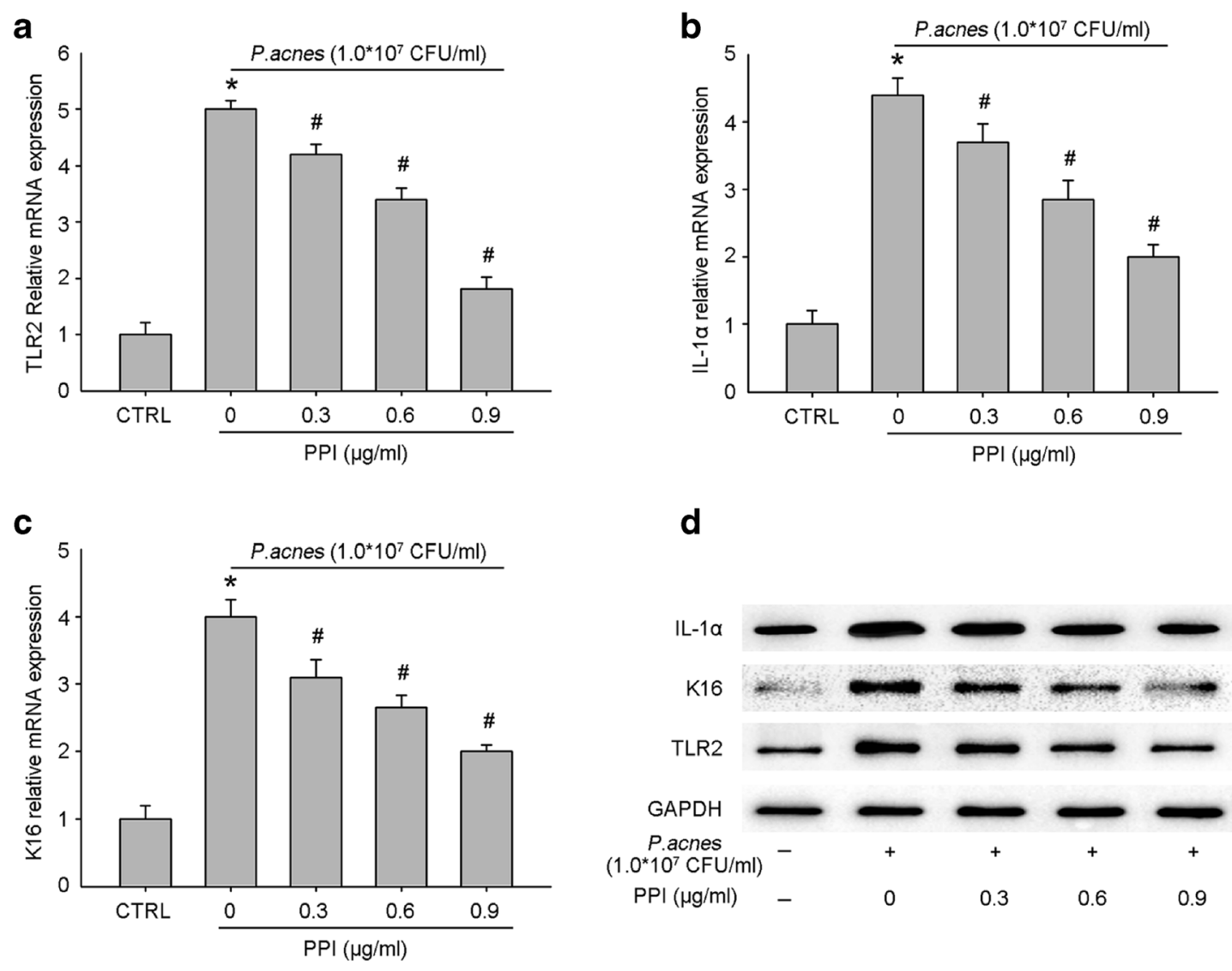

\section{d}
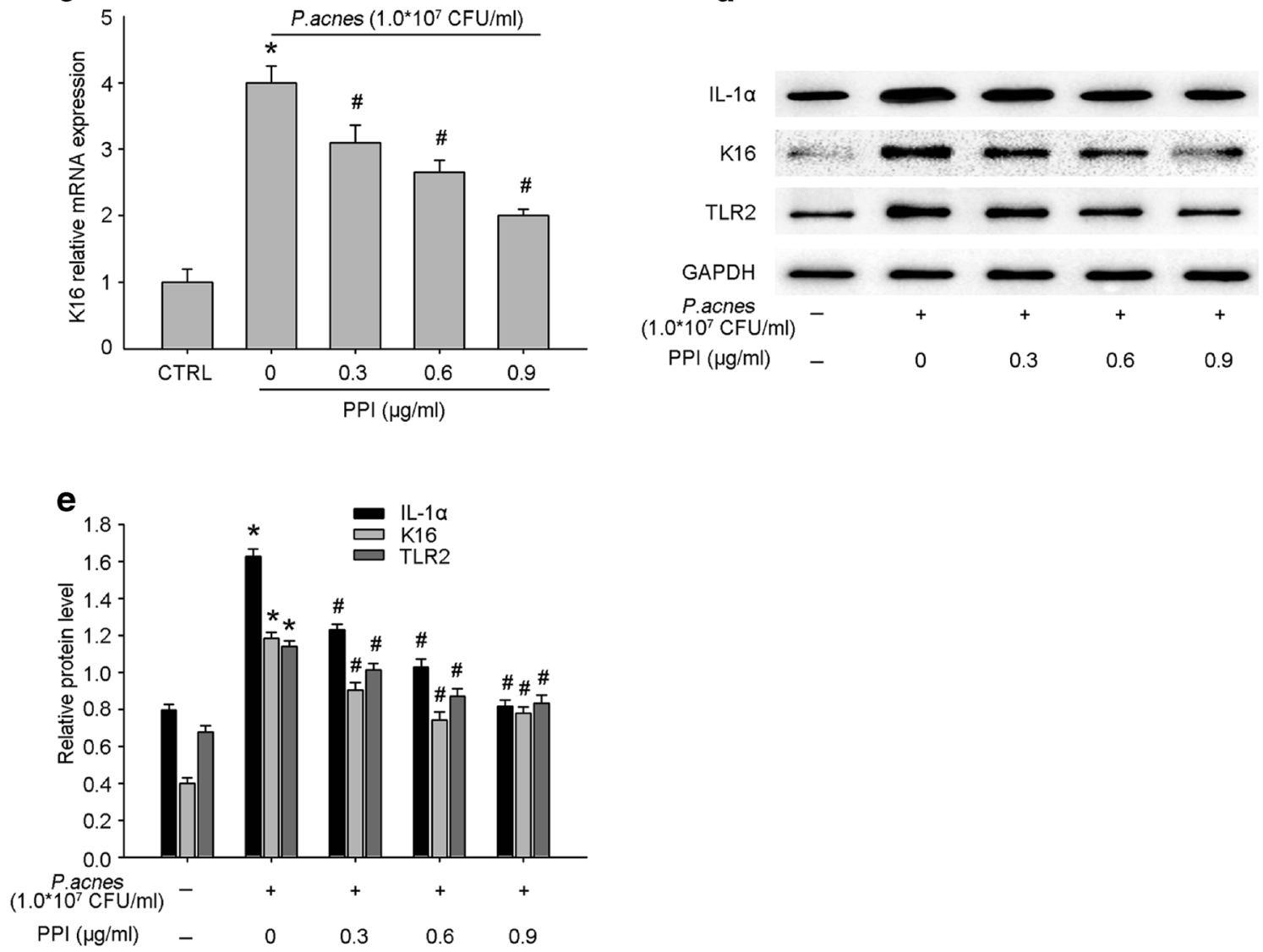

Fig. 3. Effects of PPI on the production expression level of TLR2, IL-1 $\alpha$, and K16. Cells were co-incubated with DMSO or different concentrations of PPI for $2 \mathrm{~h}$ and then stimulated by heat-killed $P$. acnes for $8 \mathrm{~h}$. A control group without $P$. acnes stimulation was done in parallel. The expression levels of TLR2 (a), IL-1 $\alpha$ (b), and K16 mRNA (c) were determined as qRT-PCR. Western blotting of TLR2, IL-1 $\alpha$, and K16 were performed (d, e). Data are the mean \pm SE $(n=3)$. $* P<0.05$ between control and each $P$. acnes-stimulated group, $\# P<0.05$ between the $P$. acnes-treated group, PPI non-treated group, and each PPItreated group.

and quantified the changes in IL- $1 \alpha$ and K16 through qRTPCR and western blotting; the results demonstrated that IL-
$1 \alpha$ and K16 expression levels were significantly increased in $\mathrm{HaCaT}$ keratinocytes following P. acnes stimulation but 
a

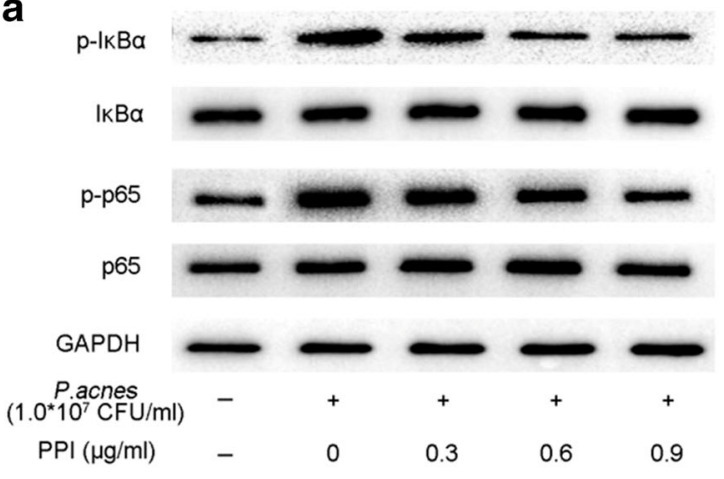

C

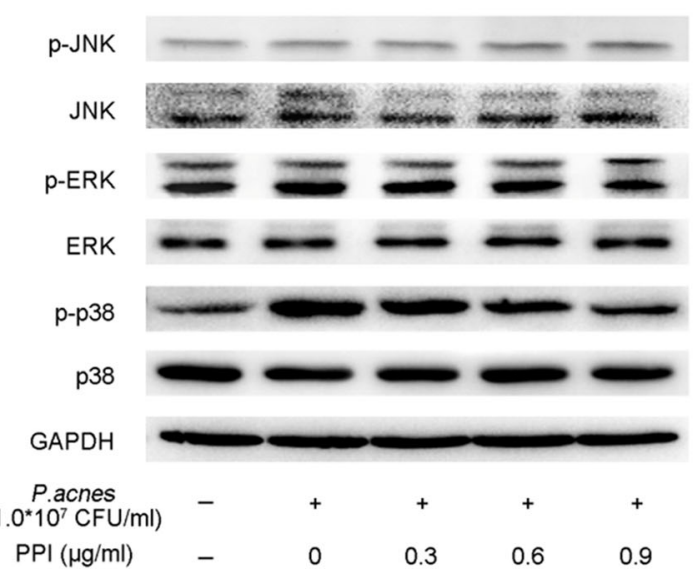

b

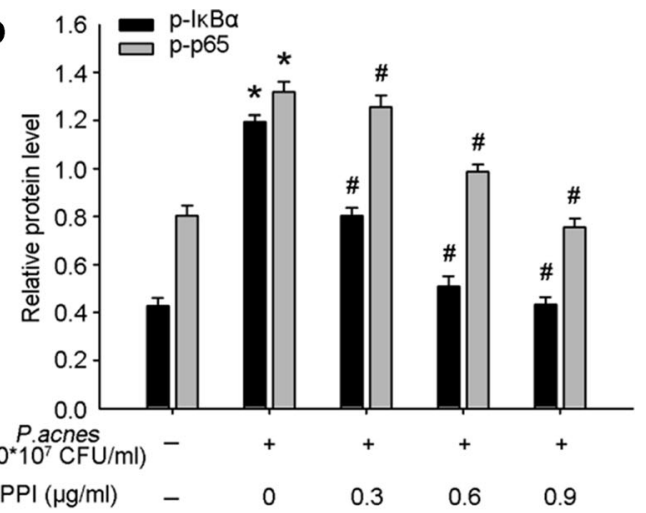

d 25

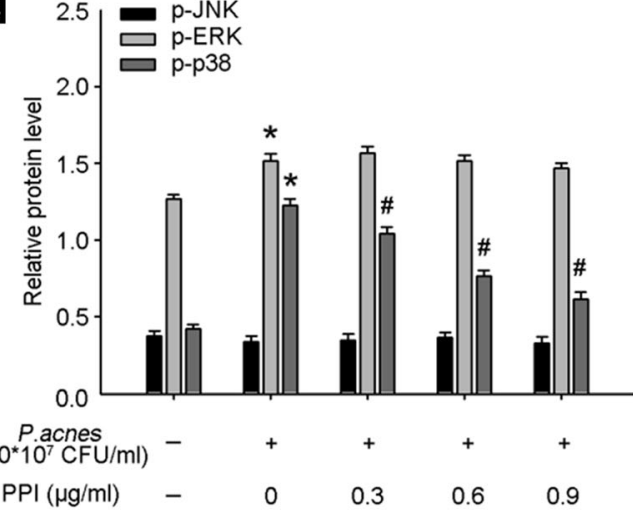

f

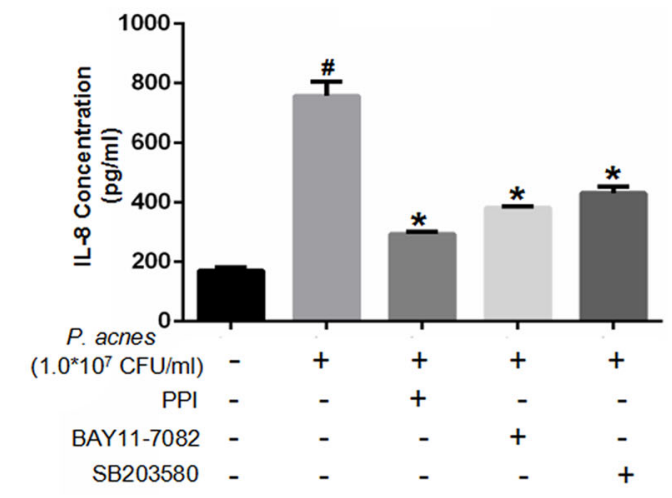

$\left.1.0^{*} 10^{7} \mathrm{CFU} / \mathrm{ml}\right)$
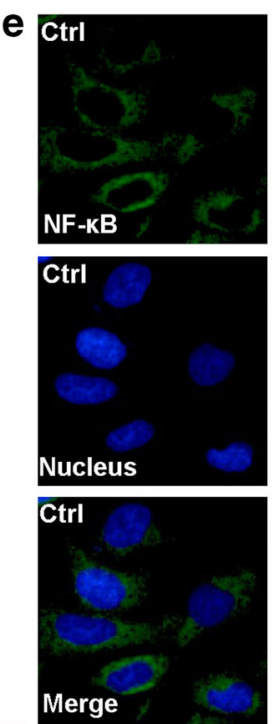

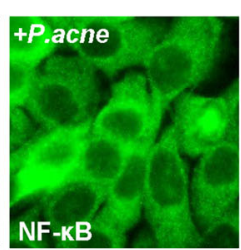

+P.acne

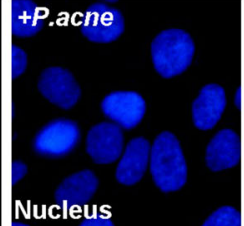

+ P.acne

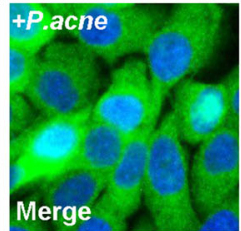

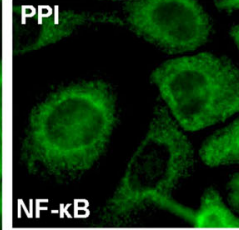

PPI

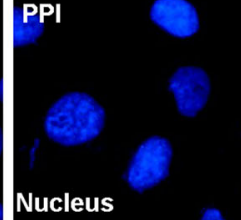

PPI

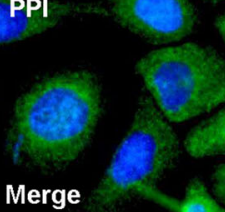

Fig. 4. Effects of PPI on the NF-kB and MAPK signaling pathways in heat-killed P. acnes-treated HaCaT keratinocytes. Cells were pretreated with 0.3, 0.6, and $0.9 \mu \mathrm{g} / \mathrm{ml}$ of PPI for $2 \mathrm{~h}$, followed by stimulation with P. acnes for $24 \mathrm{~h}$. Expression of NF- $\mathrm{kB}(\mathbf{a}, \mathbf{b})$ and MAPK (c, d) proteins was analyzed by western blotting, and the translocation of NF-KB p65 was detected by immunofluorescence (e). All data represent three independent experiments. $* P<0.05$ between control and each P. acnes-stimulated group, $\# P<0.05$ between the $P$. acnes-treated group, PPI non-treated group, and each PPI-treated group. Heat-killed $P$. acnes (107 CFU/ml) induced the secretion of IL-8, which is suppressed by BAY11-7082 $(10 \mu \mathrm{M})$, SB203580 $(20 \mu \mathrm{M})$, and PPI $(0.9 \mu \mathrm{g} / \mathrm{ml})(\mathbf{f}) . * P<0.05$ between $P$. acnes-stimulated only and treated with BAY11-7082 $(10 \mu \mathrm{M})$, SB203580 $(20 \mu \mathrm{M})$, or PPI $(0.9 \mu \mathrm{g} / \mathrm{ml})$. $\# P<0.05$ between control and each $P$. acnes-stimulated group. 
were significantly downregulated by PPI. Therefore, PPI might reverse the altered keratinization of follicular keratinocytes by decreasing IL- $1 \alpha$ levels.

The $P$. acnes-induced production of various common inflammatory cytokines represents a key pathogenic factor resulting in disease initiation and aggravation. Serum IL-6 levels are significantly higher in acne patients than in the normal population, suggesting a vital role for IL-6 in the pathogenesis of acne [20]. IL-8, a CXC chemokine with mitogenic activity in keratinocytes, is involved in the recruitment of neutrophils, the predominant cell type involved in acne inflammation-related skin lesions [16]. TNF- $\alpha$ is a multifunctional cytokine related to the regulation of acne inflammation [25]. According to our results, treatment with heat-killed $P$. acnes upregulated the expression levels of IL-6, IL-8, and TNF- $\alpha$, with a particularly robust effect on IL-8, while PPI inhibited the production of these proinflammatory cytokines in a dose-dependent manner. Thus, PPI might inhibit the inflammatory cascade by suppressing the production of these inflammatory cytokines.

P. acnes-activated TLR2 triggers the activation of the NF-KB and MAPK signaling pathways, which are responsible for inflammatory cytokine production and the innate immune response [19, 24]. The levels of phosphorylated $\mathrm{I} \kappa \mathrm{B} \alpha$ and NF- $\mathrm{KB}$ p 65 were significantly upregulated after $P$. acnes treatment but were downregulated by PPI. There are three MAPKs: p38, ERK, and JNK. The phosphorylation of p38 was significantly increased, and ERK was slightly increased in $\mathrm{HaCaT}$ keratinocytes following $P$. acnes treatment. Interestingly, PPI inhibited the P. acnes-induced phosphorylation of $\mathrm{p} 38$ in a concentration-dependent manner but did not have any effect on ERK phosphorylation. Moreover, our results showed that treatment with $P$. acnes and PPI did not have any effect on JNK phosphorylation. Subsequently, treatment with a p38 MAPK inhibitor (SB203580) or PPI decreased IL-8 expression in heat-killed $P$. acnes-treated cells. These results demonstrated that PPI inhibits IL-8 expression, possibly by suppressing NF- $\mathrm{kB}$ associated protein and p38 MAPK phosphorylation in heat-killed P. acnes-stimulated HaCaT cells. IL-8 is commonly found at high levels in acne lesions and is involved in the recruitment of neutrophils, which are the predominant cell type in acne-related lesions [16]. Nicotinamide, the amide derivative of vitamin B3, has been shown to be clinically effective in the treatment of acne by inhibiting IL-8 production [6]. Therefore, we hypothesized that the anti-inflammatory effects of PPI might be at least partly attributable to the inhibition of IL-8 production.
In conclusion, we demonstrated that PPI has protective effects against $P$. acnes-induced inflammation and hypercornification, showing the potential clinical feasibility of PPI in acne treatment.

\section{FUNDING}

This work was supported by the National Science Foundation of China (Nos. U1402223, 81460469, 81760559) and Yunnan science and technology fund(2018ZF005).

\section{COMPLIANCE WITH ETHICAL STANDARDS}

Conflict of Interest. The authors declare that they have no conflict of interest.

Ethical Approval. This article does not contain any studies with human participants or animals performed by any of the authors.

Open Access This article is distributed under the terms of the Creative Commons Attribution 4.0 International License (http://creativecommons.org/licenses/by/ $4.0 /$ ), which permits unrestricted use, distribution, and reproduction in any medium, provided you give appropriate credit to the original author(s) and the source, provide a link to the Creative Commons license, and indicate if changes were made.

\section{REFERENCES}

1. Chen, Y., J. Zhu, and W. Zhang. 2014. Antitumor effect of traditional Chinese herbal medicines against lung cancer. Anti-Cancer Drugs 25 (9): 983-991. https://doi.org/10.1097/ CAD.0000000000000127.

2. Dispenza, M.C., E.B. Wolpert, K.L. Gilliland, J.P. Dai, Z. Cong, A.M. Nelson, and D.M. Thiboutot. 2012. Systemic isotretinoin therapy normalizes exaggerated TLR-2-mediated innate immune responses in acne patients. The Journal of Investigative Dermatology 132 (9): 2198-2205. https://doi.org/10.1038/jid.2012.111.

3. Do, T.T., S. Zarkhin, J.S. Orringer, S. Nemeth, T. Hamilton, D. Sachs, J.J. Voorhees, and S. Kang. 2008. Computer-assisted alignment and tracking of acne lesions indicate that most inflammatory lesions arise from comedones and de novo. Journal of the American Academy of Dermatology 58 (4): 603-608. https://doi.org/10.1016/ j.jaad.2007.12.024.

4. Dong, R., J. Guo, Z. Zhang, Y. Zhou, and Y. Hua. 2018. Polyphyllin I inhibits gastric cancer cell proliferation by downregulating the expression of fibroblast activation protein alpha (FAP) and hepatocyte growth factor (HGF) in cancer-associated fibroblasts. Biochemical and Biophysical Research Communications 497 (4): 11291134. https://doi.org/10.1016/j.bbrc.2018.02.193. 
5. Global Burden of Disease Study Collaborators. 2015. Global, regional, and national incidence, prevalence, and years lived with disability for 301 acute and chronic diseases and injuries in 188 countries, 1990-2013: a systematic analysis for the Global Burden of Disease Study 2013. Lancet 386 (9995): 743-800. https://doi.org/ 10.1016/S0140-6736(15)60692-4.

6. Grange, P.A., J. Raingeaud, V. Calvez, and N. Dupin. 2009. Nicotinamide inhibits Propionibacterium acnes-induced IL-8 production in keratinocytes through the NF-kappaB and MAPK pathways. Journal of Dermatological Science 56 (2): 106-112. https:// doi.org/10.1016/j.jdermsci.2009.08.001.

7. Gu, L., J. Feng, H. Xu, M. Luo, and D. Su. 2013. Polyphyllin I inhibits proliferation and metastasis of ovarian cancer cell line HO8910PM in vitro. Journal of Traditional Chinese Medicine 33 (3): 325-333.

8. Guy, R., M.R. Green, and T. Kealey. 1996. Modeling acne in vitro. The Journal of Investigative Dermatology 106 (1): 176-182.

9. Hay, R.J., N.E. Johns, H.C. Williams, I.W. Bolliger, R.P. Dellavalle, D.J. Margolis, R. Marks, L. Naldi, M.A. Weinstock, S.K. Wulf, C. Michaud, C. J.L. Murray, and M. Naghavi. 2014. The global burden of skin disease in 2010: an analysis of the prevalence and impact of skin conditions. The Journal of Investigative Dermatology 134 (6): 1527-1534. https://doi.org/10.1038/jid.2013.446.

10. Heymann, W.R. 2006. Toll-like receptors in acne vulgaris. Journal of the American Academy of Dermatology 55 (4): 691-692. https:// doi.org/10.1016/j.jaad.2006.05.049.

11. Huang, Y.C., C.H. Yang, T.T. Li, C.C. Zouboulis, and H.C. Hsu. 2015. Cell-free extracts of Propionibacterium acnes stimulate cytokine production through activation of p38 MAPK and Toll-like receptor in SZ95 sebocytes. Life Sciences 139: 123-131. https:// doi.org/10.1016/j.lfs.2015.07.028.

12. Jarrousse, V., N. Castex-Rizzi, A. Khammari, M. Charveron, and B. Dreno. 2007. Zinc salts inhibit in vitro Toll-like receptor 2 surface expression by keratinocytes. European Journal of Dermatology 17 (6): 492-496. https://doi.org/10.1684/ejd.2007.0263.

13. Jeremy, A.H., D.B. Holland, S.G. Roberts, K.F. Thomson, and W.J. Cunliffe. 2003. Inflammatory events are involved in acne lesion initiation. The Journal of Investigative Dermatology 121 (1): 2027. https://doi.org/10.1046/j.1523-1747.2003.12321.x.

14. Kim, J., M.T. Ochoa, S.R. Krutzik, O. Takeuchi, S. Uematsu, A.J. Legaspi, H.D. Brightbill, D. Holland, W.J. Cunliffe, S. Akira, P.A. Sieling, P.J. Godowski, and R.L. Modlin. 2002. Activation of tolllike receptor 2 in acne triggers inflammatory cytokine responses. Journal of Immunology 169 (3): 1535-1541.

15. Kwon, H.H., J.Y. Yoon, S.Y. Park, S. Min, Y.I. Kim, J.Y. Park, Y.S. Lee, D.M. Thiboutot, and D.H. Suh. 2015. Activity-guided purification identifies lupeol, a pentacyclic triterpene, as a therapeutic agent multiple pathogenic factors of acne. The Journal of Investigative Dermatology 135 (6): 1491-1500. https://doi.org/10.1038/ jid.2015.29.

16. Layton, A.M., C. Morris, W.J. Cunliffe, and E. Ingham. 1998. Immunohistochemical investigation of evolving inflammation in lesions of acne vulgaris. Experimental Dermatology 7 (4): 191-197.

17. Lee, W.R., K.H. Kim, H.J. An, J.Y. Kim, Y.C. Chang, H. Chung, Y.Y. Park, M.L. Lee, and K.K. Park. 2014. The protective effects of melittin on Propionibacterium acnes-induced inflammatory responses in vitro and in vivo. The Journal of Investigative Dermatology 134 (7): 1922-1930. https://doi.org/10.1038/jid.2014.75.

18. Li, W.H., L. Zhang, P. Lyte, K. Rodriguez, D. Cavender, and M.D. Southall. 2015. p38 MAP kinase inhibition reduces
Propionibacterium acnes-induced inflammation in vitro. Dermatology and Therapy (Heidelberg) 5 (1): 53-66. https://doi.org/10.1007/ s13555-015-0072-7.

19. Nguyen, C.T., S.K. Sah, and T.Y. Kim. 2018. Inhibitory effects of superoxide dismutase 3 on Propionibacterium acnes-induced skin inflammation. Scientific Reports 8 (1): 4024. https://doi.org/ 10.1038/s41598-018-22132-z.

20. Salamon, M., A. Sysa-Jedrzejowska, J. Lukamowicz, M. Lukamowicz, E. Swiatkowska, and A. Wozniacka. 2008. Concentration of selected cytokines in serum of patients with acne rosacea. Przeglad Lekarski 65 (9): 371-374.

21. Selway, J.L., T. Kurczab, T. Kealey, and K. Langlands. 2013. Tolllike receptor 2 activation and comedogenesis: implications for the pathogenesis of acne. BMC Dermatology 13: 10. https://doi.org/ 10.1186/1471-5945-13-10.

22. Shaheen, B., and M. Gonzalez. 2013. Acne sans P. acnes. Journal of the European Academy of Dermatology and Venereology 27 (1): 110. https://doi.org/10.1111/j.1468-3083.2012.04516.x.

23. Suh, D.H., and H.H. Kwon. 2015. What's new in the physiopathology of acne? The British Journal of Dermatology 172 (Suppl 1): 1319. https://doi.org/10.1111/bjd.13634.

24. Takeuchi, O., and S. Akira. 2010. Pattern recognition receptors and inflammation. Cell 140 (6): 805-820. https://doi.org/10.1016/ j.cell.2010.01.022.

25. Taylor, M., R. Porter, and M. Gonzalez. 2014. Intense pulsed light may improve inflammatory acne through TNF-alpha down-regulation. Journal of Cosmetic and Laser Therapy 16 (2): 96-103. https:// doi.org/10.3109/14764172.2013.864198.

26. The State Pharmacopoeia Commission. 2015. Chinese pharmacopoeia. Beijing: Chinese Pharmacopoeia Commission.

27. Walsh, T.R., J. Efthimiou, and B. Dreno. 2016. Systematic review of antibiotic resistance in acne: an increasing topical and oral threat. The Lancet Infectious Diseases 16 (3): e23-e33. https://doi.org/ 10.1016/S1473-3099(15)00527-7.

28. Wang, Y.Y., A.R. Ryu, S. Jin, Y.M. Jeon, and M.Y. Lee. 2017. Chlorin e6-mediated photodynamic therapy suppresses P. acnesinduced inflammatory response via NFkappaB and MAPKs signaling pathway. PLoS One 12 (1): e0170599. https://doi.org/10.1371/ journal.pone.0170599.

29. Yang, L., X. Fan, T. Cui, E. Dang, and G. Wang. 2017. Nrf2 promotes keratinocyte proliferation in psoriasis through upregulation of keratin 6, keratin 16, and keratin 17. The Journal of Investigative Dermatology 137 (10): 2168-2176. https://doi.org/ 10.1016/j.jid.2017.05.015.

30. Yoon, J.Y., H.H. Kwon, S.U. Min, D.M. Thiboutot, and D.H. Suh 2013. Epigallocatechin-3-gallate improves acne in humans by modulating intracellular molecular targets and inhibiting P. acnes. The Journal of Investigative Dermatology 133 (2): 429-440. https:// doi.org/10.1038/jid.2012.292.

31. Zhang, Jin Yu, Yuan Zhong Wang, Yan Li Zhao, Shao Bing Yang, Zhi Tian Zuo, Mei Quan Yang, Ji Zhang, Wei Ze Yang, Tian Mei Yang, and Hang Jin. 2011. Phytochemicals and bioactivities of Paris species. Journal of Asian Natural Products Research 13 (7): 670681.

32. Zhao, Y., C.L. Wang, R.M. Li, T.Q. Hui, Y.Y. Su, Q. Yuan, X.D. Zhou, and L. Ye. 2014. Wnt5a promotes inflammatory responses via nuclear factor kappaB (NF-kappaB) and mitogen-activated protein kinase (MAPK) pathways in human dental pulp cells. The Journal of Biological Chemistry 289 (30): 21028-21039. https://doi.org/ 10.1074/jbc.M113.546523. 